\title{
Sites of Latest Mechanical Activation as Assessed by SPECT Myocardial Perfusion Imaging in Ischemic and Dilated Cardiomyopathy Patients with LBBB
}

\author{
Xianhe Lin, MD, $\mathrm{PhD}^{1}$, Huiqin $\mathrm{Xu}, \mathrm{MD}^{2}$, Xuefeng Zhao, $\mathrm{MD}^{2}$, and Ji Chen, PhD, FACC ${ }^{3}$ \\ ${ }^{1}$ Department of Cardiology, Anhui Medical University, Hefei, Anhui, China \\ ${ }^{2}$ Department of Nuclear Medicine, Anhui Medical University, Hefei, Anhui, China \\ ${ }^{3}$ Department of Radiology and Imaging Sciences, Emory University, Atlanta, GA, USA
}

\begin{abstract}
Objective-Sites of latest mechanical activation (SOLA) have been recognized as optimal leftventricular (LV) lead positions for cardiac resynchronization therapy (CRT). This study was aimed to investigate SOLA in ischemic cardiomyopathy (ICM) and dilated cardiomyopathy (DCM) patients with left bundle branch block (LBBB).
\end{abstract}

Methods-Sixty-four consecutive LBBB patients (47 DCM, 17 ICM), who met the standard indications for CRT and underwent resting SPECT myocardial perfusion imaging (MPI), were selected. Phase analysis was used to assess LV dyssynchrony and SOLA. The Emory Cardiac Toolbox was used to measure perfusion defects. LV dyssynchrony and SOLA were compared between the DCM patients with wide ( $\geq 150 \mathrm{~ms}$ ) and moderate (120-150 ms) QRS durations (QRSd). The relationship between SOLA and perfusion defects was analyzed in the ICM patients.

Results-The DCM patients with wide QRSd had significantly more LV dyssynchrony than those with moderate QRSd. Lateral SOLA were significantly more frequent in the DCM patients with wide QRSd than those with moderate QRSd (96\% vs. 62\%, p=0.010). In the ICM patients, SOLA were either in the scar segments $(82 \%)$ or in the segments immediately adjacent to the scar segments (18\%), regardless of QRSd.

Conclusion-Lateral SOLA were more frequent in the DCM patients with wide QRSd than those with moderate QRSd. Such relationship was not observed in the ICM patients, where SOLA were associated with scar location rather than QRSd. These findings support the use of SPECT MPI to aid the selection of potential CRT responders and guide LV lead placement.

\section{Keywords}

Cardiac resynchronization therapy; SPECT myocardial perfusion imaging; phase analysis; LV dyssynchrony

\footnotetext{
Address of the Correspondence Author: Ji Chen, PhD, FACC, FASNC, Department of Radiology and Imaging Sciences, Emory University, 1364 Clifton Road NE, Atlanta, GA, 30322, USA, Tel: 1-404-712-4024, Fax: 1-404-727-3488, jchen22@emory.edu. Address of the Other Authors: Xianhe Lin, MD, PhD, Department of Cardiology, The First Affiliated Hospital of Anhui Medical University, 218 Jixi Road, Hefei, Anhui, 230022, China, Huiqin Xu, MD and Xuefeng Zhao, MD, Department of Nuclear Medicine,

The First Affiliated Hospital of Anhui Medical University, 218 Jixi Road, Hefei, Anhui, 230022, China
} 


\section{Introduction}

Cardiac resynchronization therapy (CRT) has been shown to benefit heart failure patients in large randomized trials [1-8]. The current standard indications for CRT are New York Heart Association (NYHA) class II to IV, left ventricular (LV) ejection fraction (LVEF) $₫ 35 \%$, and sinus rhythm with QRS duration $\geq 120 \mathrm{~ms}$ on electrocardiogram (ECG) [9]. However, based on the standard indications, up to $30-40 \%$ of the patients having CRT do not respond with improved clinical symptom and/or LV function [4-5, 10-12].

One of the main reasons of CRT non-response is suboptimal LV lead position [13]. According to the guidelines [9], LV leads are recommended to be placed in the lateral or posterolateral wall, which is presumably the site of latest mechanical activation in patients with left bundle branch block (LBBB) and a prolonged QRS duration (QRSd). Since the most widely accepted mechanism of CRT is mechanically resynchronization of both ventricles by electrical stimulation of the myocardium, pacing the lateral or posterolateral wall activates these late-activated areas earlier and thus may restore mechanical synchrony of the entire ventricle. This mechanism was demonstrated in a large clinical study with 496 CRT patients [14]. In that study CRT improved LVEF significantly better in the patients with LBBB and QRSd $\geq 150 \mathrm{~ms}(12 \pm 12 \%)$ than the patients with LBBB and QRSd $<150 \mathrm{~ms}$ $(8 \pm 10 \%)$, the patients with non-LBBB and QRSd $\geq 150 \mathrm{~ms}(5 \pm 9 \%)$, and the patients with non-LBBB and QRSd $<150 \mathrm{~ms}(3 \pm 11 \%)(\mathrm{p}<0.0001)$, respectively. The Resynchronization Reverses Remodeling in Systolic Left Ventricular Dysfunction (REVERSE) trial with 610 CRT patients also showed that LBBB and QRS prolongation were significant markers of LV reverse remodeling and clinical benefit with CRT in mild heart failure patients [15].

Noteworthy, electrical activation/conduction can be interfered by myocardial scar, which has much lower electricity than viable myocardium. A study showed that in patients with dilated cardiomyopathy (DCM) electrical activation patterns corresponded with the 12-lead ECG with a homogeneous spread of activation wavefront and the latest activation in the lateral wall [16]. On the contrary, electrical activation patterns were quite variable in patients with ischemic cardiomyopathy (ICM) [16]. Such variable electrical activation patterns may result in variable sites of latest mechanical activation in ICM patients, and may consequently affect their CRT response. In fact, a large clinical study with 503 CRT patients showed that DCM patients had greater improvement in LVEF and LV reverse remodeling and sustained a greater survival benefit than ICM patients [17].

The aim of this study was to investigate the sites of latest mechanical activation in DCM and ICM patients with LBBB. This study used a relatively new technique, phase analysis of SPECT myocardial perfusion imaging (MPI) [18], which has been shown to identify the sites of latest mechanical activation as the optimal LV lead positions with enhanced CRT response [19]. 


\section{Materials and Methods}

\section{Patients}

This study included 64 consecutive patients selected from the nuclear medicine databases at Anhui Medical University ( $\mathrm{N}=30)$ and Emory University $(\mathrm{N}=34)$. The selected patients had LBBB, met the standard indications of CRT, and underwent gated SPECT MPI. Among these patients, 47 had DCM and 17 had ICM. The DCM patients had no prior history of myocardial infarction. Thirty-two of the $47 \mathrm{DCM}$ patients had coronary angiograms that did not show $>50 \%$ of stenosis in any coronary arteries. Four of the remaining 15 DCM patients had CT angiograms that did not show $>50 \%$ of stenosis in any coronary arteries. The SPECT MPI studies of the remaining 9 DCM patients were interpreted as having normal myocardial perfusion. All of the ICM patients had coronary angiograms that confirmed the presence of $>50 \%$ of stenosis in at least one coronary artery. Table 1 shows the characteristics of the selected patients.

\section{SPECT Myocardial Perfusion Imaging}

Each patient underwent a standard resting SPECT MPI. The images were acquired using mainstream dual-head SPECT systems (Discovery VH and Millennium MG, General Electric Healthcare) with low-energy-high-resolution collimators and with standard acquisition parameters (step and shoot format with 25-30 seconds per stop, 60 projections over $180^{\circ}$ orbit, and 8-bin gating).

The SPECT images were reconstructed using standard iterative reconstruction (ordered subset expectation maximization with 3 iterations and 10 subsets) and Butterworth filtering (cutoff frequency of $0.4 \mathrm{~cm} / \mathrm{cycle}$ and power of 10 ). The reconstructed images were reoriented into short-axis slices and then submitted to the phase analysis to measure LV dyssynchrony [18] and sites of latest mechanical activation [19] and to the Emory Cardiac Toolbox (Emory University, Atlanta, GA, USA) to measure myocardial perfusion defects [20].

\section{Image Analysis}

Phase analysis of SPECT MPI was developed at Emory University to automatically and quantitatively measure LV dyssynchrony [18] and has been extensively studied in the past several years [21]. Briefly, it utilized the partial volume effect in the SPECT MPI images, where the regional maximum counts are proportional to the regional myocardial wall thickness [22]. By approximating the regional maximum counts over the cardiac cycle with the Fourier first-harmonic function, a regional phase was calculated to represent the onset of myocardial wall thickening (i.e., the time of mechanical activation) of the region [18] (Figure 1A). Once regional phases were calculated from all regions sampled over the left ventricle (usually, >600 samples), they were displayed in a phase polar map (Figure 1B). The heterogeneity of the phase distribution over the left ventricle represented LV mechanical dyssynchrony, which was characterized quantitatively by two parameters: phase standard deviation (PSD) and phase histogram bandwidth (PHB) [18]. These parameters were shown to correlate well with the LV dyssynchrony parameters measured by tissue Doppler echocardiography [23]. Through segmenting the phase poplar map with the 17- 
segment model [24], LV regional mechanical activation was characterized by the mean phases of the segments, as shown in Figures 2 and 3. The site of latest mechanical activation was defined as the segment with the largest mean phase among the 17 segments.

Myocardial perfusion defects were automatically and quantitatively measured using the Emory Cardiac Toolbox with its standard Tc-99m normal database [20]. A 5-point score (0: Normal, 1: Equivocal, 2: Moderately Reduced, 3: Severely Reduced, 4: Absent) was calculated for each of the 17 segments. The segments with a perfusion score of 3 or 4 were considered as myocardial scar. Figures 2 and 3 demonstrate the quantitative methods to measure regional mechanical activation and myocardial perfusion defect in the 17-segment model in a DCM patient and an ICM patient, respectively.

\section{Statistical Analysis}

Continuous variables were expressed as mean \pm standard deviation. Unpaired $t$ test was used to compare the LV dyssynchrony parameters (PSD and PHB) among different patient groups. Chi-square test was used to compare the frequencies of lateral sites of latest mechanical activation among different patient groups. $\mathrm{P}<0.05$ indicated the statistical significance.

\section{Results}

Among the 47 DCM patients, 38 patients (81\%) had the sites of latest mechanical activation in the lateral segments (as depicted in a DCM example in Figure 2), whereas in the other 9 patients (19\%) the sites of latest mechanical activation were not in these lateral segments. Among the 47 DCM patients, 26 patients had wide QRSd ( $\geq 150 \mathrm{~ms})$, whereas the other 21 patients had moderate QRSd (120-150ms). Table 2 compares the LV dyssynchrony parameters and frequencies of lateral latest mechanical activation between these two groups. The LV dyssynchrony parameters were significantly larger in the patients with wide QRSd than those with moderate QRSd (PSD: $45.4 \pm 18.5$ vs. 33.4 \pm 16.2 , $\mathrm{p}=0.023$; PHB: $148.4 \pm 72.8$ vs. 103.2 $\pm 54.5, \mathrm{p}=0.019)$. The sites of latest mechanical activation were significantly more frequent in the lateral wall in the patients with wide QRSd than those with moderate QRSd ( 25 out of $26,96 \%$ vs. 13 out of $21,62 \%, \mathrm{p}=0.010$ ). A DCM example with wide QRSd and lateral latest mechanical activation is shown in Figure 2.

Table 3 compares the LV dyssynchrony parameters and QRSd between the ICM and DCM patients and shows no statistically significant differences in these parameters between the two groups (PSD: $50.6 \pm 20.6$ vs. $40.0 \pm 18.3$, $\mathrm{p}=0.073$; PHB: $171.9 \pm 83.8$ vs. $128.2 \pm 68.5$, $\mathrm{p}=0.066$ ). Table 3 also shows the comparisons when dividing the DCM patients into the two sub-groups with wide and moderate QRSd, respectively. Despite statistically insignificant difference in QRSd between the ICM group and the DCM group with moderate QRSd, the former had significantly more LV dyssynchrony than the latter (PSD: 50.6 \pm 20.6 vs. $33.4 \pm 16.2$, p=0.009; PHB: $171.9 \pm 83.8$ vs. $103.2 \pm 54.5, \mathrm{p}=0.007$ ), indicating that myocardial scar was a factor to deteriorate LV synchrony. Despite significantly shorter QRSd in the ICM group than that in the DCM group with wide QRSd, there was no statistically significant difference in LV dyssynchrony between them (PSD: 50.6 \pm 20.6 vs. $45.4 \pm 18.5$, $\mathrm{p}=0.401$; PHB: $171.9 \pm 83.8$ vs. $148.4 \pm 72.8, \mathrm{p}=0.352$ ), also indicating that myocardial scar 
was a factor to deteriorate LV synchrony. These findings were consistent with a previous study that showed the severity and extent of myocardial scar was an independent predictor of LV dyssynchrony in patients with ischemic heart disease [25].

In the ICM patients the sites of latest mechanical activation were associated with the location of myocardial scar, regardless of QRSd. In 14 of the 17 ICM patients (82\%), their sites of the latest mechanical activation were the scar segments. In the other 3 patients, their sites of the latest mechanical activation were in the segments immediately adjacent to the scar segments. In the 7 ICM patients with wide QRSd ( $\geq 150 \mathrm{~ms}$ ), only 1 patient had lateral site of latest mechanical activation and lateral scar, whereas the other 6 patients had nonlateral scar and non-lateral site of latest mechanical activation. Figure 3 shows an ICM example, who had wide QRSd (160 ms) but apical latest mechanical activation due to the apical scar.

\section{Discussion}

This study was the first SPECT MPI study to investigate the relations among LBBB and QRSd, myocardial scar, and site of latest mechanical activation on the left ventricle. This study showed that LBBB with wide QRSd caused more frequent lateral latest mechanical activation in the DCM patients, but not in the ICM patients where the site of latest mechanical activation is associated with the scar location rather than QRSd. These findings were not surprising, because conceptually electrical activation/conduction can be delayed in the lateral wall due to LBBB and can be interfered by myocardial scar [16]. Nevertheless, these findings had important implications for using SPECT MPI to aid the selection of potential CRT responders and guide LV lead placement.

Selecting appropriate patients for CRT has been widely studied. Selection of patients based on QRS duration is not optimal. QRS duration is not predictive to CRT response; instead, mechanical dyssynchrony is important for response to CRT [26]. LV dyssynchrony has been shown as an essential parameter for selecting CRT responders by echocardiography [27-28], magnetic resonance imaging [29], gated SPECT MPI [30], and gated blood pool imaging [31]. In addition, the presence of extensive LV scar tissue may hamper response to CRT. Patients with extensive scar tissue (irrespective of the location) have been shown to have a low likelihood of response to CRT [32-33]. Noteworthy, these studies were based on the standard CRT implantation approach, which usually placed the LV lead in the lateral/ posterolateral wall. As a change in LV lead position by as little as $2 \mathrm{~cm}$ may impact the response to CRT [34], it is an important factor and must be considered for CRT response.

The optimal LV lead position has been recognized as the site of latest mechanical activation. In a study with 244 CRT patients, the patients with a concordant LV lead position (i.e., the LV lead placed in the site of latest mechanical activation measured by echocardiography) had significantly better LV reverse remodeling and long-term outcome post CRT than the patients with a discordant LV lead position [35]. Another study reported that the LV lead positioned at the site of latest mechanical activation measured by SPECT MPI resulted in superior CRT response [19]. The conventional CRT practice places the LV lead in the lateral or posterolateral wall, which is presumably the site of latest mechanical activation due to 
LBBB and QRS prolongation. This study showed that such presumption is more likely true in the DCM patients with wide QRSd ( $\geq 150 \mathrm{~ms}$ ) than in the DCM patients with moderate QRSd (120-150 ms) and in the ICM patients. Therefore, this study supports the use of SPECT MPI to differentiate DCM and ICM patients to aid the selection of potential CRT responders.

This study also showed that the site of latest mechanical activation is associated with the scar location rather than QRSd in the ICM patients. This finding indicated the importance of integrating the assessment of regional mechanical activation and myocardial viability to identify the optimal LV lead position, because pacing scar leads to prolonged and fragmented QRS and mechanical dyssynchrony [36-37] and decreases CRT response [38]. To integrate the assessment of regional mechanical activation and myocardial viability, SPECT MPI has an advantage over other imaging modalities, because both regional mechanical activation and myocardial viability can be measured from a single resting SPECT MPI scan. In fact, a pilot study with 44 CRT patients showed that the patients with the LV leads placed in a viable and latest activated segment measured by SPECT MPI had favorable acute CRT response and long-term outcome [39]. Therefore, this study supports the use of SPECT MPI to comprehensively assess both regional mechanical activation and myocardial viability to guide LV lead placement.

The clinical implications for using SPECT MPI to aid the selection of potential CRT responders and guide LV lead placement were further demonstrated in Figure 4, which shows both pre-CRT and post-CRT SPECT MPI images of the same patient in Figure 2. This patient had a standard CRT implantation within one month post the first SPECT scan, and the second SPECT scan was acquired about eleven months post CRT. This patient had DCM, LBBB and wide QRSd (170 ms), and LV dyssynchrony. Her lateral wall was viable and had the latest mechanical activation, as shown in Figure 2. After the standard CRT therapy this patient showed remarkable improvement in LVEF and reduction in LV enddiastolic and end-systolic volumes, representing a positive CRT response and LV reserve remodeling.

The main limitation of this study was the lack of follow-up data in all enrolled patients to perform outcome analysis. Although the patient examples in Figure 4 compared the preCRT and post-CRT SPECT MPI images and demonstrated the important clinical implications of SPECT MPI for improving CRT response, these implications should be considered observational and need to be validated prospectively with follow-up data. Another limitation was the relatively small sample size of the ICM group. Nevertheless, it demonstrated remarkably variable relationships among sites of latest mechanical activation, QRS duration, and scar location in ICM. Such variations had important implications for CRT patient selection and need to be further investigated in a larger study.

\section{Conclusion}

The site of latest mechanical activation was more likely located in the lateral wall in the LBBB patients with DCM and wide QRSd ( $\geq 150 \mathrm{~ms}$ ) than in those with DCM and moderate QRSd (120-150 ms). Such relationship was not observed in the LBBB patients with ICM, 
where the site of latest mechanical activation was associated with the scar location rather than QRSd. These findings not only confirmed the concept that electrical activation/ conduction can be delayed in the lateral wall due to LBBB and can be interfered by myocardial scar, but also provided an insight into the generally better CRT responses in LBBB patients with DCM and wide QRS than those with narrow QRS and/or ICM.

Therefore, these findings support the use of SPECT MPI to aid the selection of potential CRT responders and guide LV lead placement and need to be validated prospectively with follow-up data.

\section{Acknowledgments}

This study was supported in part by a USA NIH grant (1R01HL094438, PI: Ji Chen, PhD). Dr. Chen receives royalties from the sale of the Emory Cardiac Toolbox with SyncTool. The terms of this arrangement have been approved by Emory University in accordance with its conflict-of-interest practice.

\section{References}

1. Lozano I, Bocchiardo M, Achtelik M, Gaita F, Trappe HJ, Daoud E, Hummel J, Duby C, Yong P. Impact of biventricular pacing on mortality in a randomized crossover study of patients with heart failure and ventricular arrhythmias. Pacing Clin Electrophysiol. 2000; 23:1711-1712. [PubMed: 11139906]

2. Cazeau S, Leclercq C, Lavergne T, Walker S, Varma C, Linde C, Garrigue S, Kappenberger L, Haywood GA, Santini M, Bailleul C, Daubert JC. Effects of multisite biventricular pacing in patients with heart failure and intraventricular conduction delay. N Engl J Med. 2001; 344:873-880. [PubMed: 11259720]

3. Auricchio A, Stellbrink C, Sack S, Block M, Vogt J, Bakker P, Huth C, Schondube F, Wolfhard U, Bocker D, Krahnefeld O, Kirkels H. Long-term clinical effect of hemodynamically optimized cardiac resynchronization therapy in patients with heart failure and ventricular conduction delay. J Am Coll Cardiol. 2002; 39:2026-2033. [PubMed: 12084604]

4. Abraham WT, Fisher WG, Smith AL, Delurgio DB, Leon AR, Loh E, Kocovic DZ, Packer M, Clavell AL, Hayes DL, Ellestad M, Trupp RJ, Underwood J, Pickering F, Truex C, McAtee P, Messenger J. Cardiac resynchronization in chronic heart failure. N Engl J Med. 2002; 346:18451853. [PubMed: 12063368]

5. Young JB, Abraham WT, Smith AL, Leon AR, Lieberman R, Wilkoff B, Candy RC, Schroeder JS, Liem LB, Hall S, Wheelan K. Combined cardiac resynchronization and implantable cardioversion defibrillation in advanced chronic heart failure: the MIRACLE ICD Trial. JAMA. 2003; 289:26852694. [PubMed: 12771115]

6. Auricchio A, Stellbrink C, Butter C, Sack S, Vogt J, Misier AR, Bocker D, Block M, Kirkels JH, Kramer A, Huvelle E. Clinical efficacy of cardiac resynchronization therapy using left ventricular pacing in heart failure patients stratified by severity of ventricular conduction delay. J Am Coll Cardiol. 2003; 42:2109-2116. [PubMed: 14680736]

7. Bristow MR, Saxon LA, Boehmer J, Krueger S, Kass DA, De Marco T, Carson P, DiCarlo L, DeMets D, White BG, DeVries DW, Feldman AM. Cardiac-resynchronization therapy with or without an implantable defibrillator in advanced chronic heart failure. N Engl J Med. 2004; 350:2140-2150. [PubMed: 15152059]

8. Cleland JG, Daubert JC, Erdmann E, Freemantle N, Gras D, Kappenberger L, Tavazzi L. The effect of cardiac resynchronization on morbidity and mortality in heart failure. N Engl J Med. 2005; 352:1539-1549. [PubMed: 15753115]

9. 2012 ACCF/AHA/HRS focused update incorporated into the ACCF/AHA/HRS 2008 guidelines for device-based therapy of cardiac rhythm abnormalities: a report of the American College of Cardiology Foundation/American Heart Association Task Force on Practice Guidelines and the Heart Rhythm Society. Circulation. 2013; 127:e283-e352. [PubMed: 23255456] 
10. Bax JJ, Bleeker GB, Marwick TH, Molhoek SG, Boersma E, Steendijk P, van der Wall EE, Schalij MJ. Left ventricular dyssynchrony predicts response and prognosis after cardiac resynchronization therapy. J Am Coll Cardiol. 2004; 44:1834-1840. [PubMed: 15519016]

11. Yu CM, Fung JW, Zhang Q, Chan CK, Chan YS, Lin H, Kum LC, Kong SL, Zhang Y, Sanderson JE. Tissue Doppler imaging is superior to strain rate imaging and postsystolic shortening on the prediction of reverse remodeling in both ischemic and nonischemic heart failure after cardiac resynchronization therapy. Circulation. 2004; 110:66-73. [PubMed: 15197148]

12. Yu CM, Zhang Q, Chan YS, Chan CK, Yip GW, Kum LC, Wu EB, Lee PW, Lam YY, Chan S, Fung JW. Tissue Doppler velocity is superior to displacement and strain mapping in predicting left ventricular reverse remodeling response after cardiac resynchronization therapy. Heart. 2006; 92:1452-1456. [PubMed: 16621873]

13. Donal E, de Chillou C, Magnin-Poull I, Leclercq C. Imaging in cardiac resynchronization therapy: what does the clinician need? Europace. 2008; 10(Suppl 3):iii70-iii72. [PubMed: 18955402]

14. Dupont M, Rickard J, Baranowski B, Varma N, Dresing T, Gabi A, Finucan M, Mullens W, Wilkoff BL, Tang WH. Differential response to cardiac resynchronization therapy and clinical outcomes according to QRS morphology and QRS duration. J Am Coll Cardiol. 2012; 60:592598. [PubMed: 22796255]

15. Gold MR, Thebault C, Linde C, Abraham WT, Gerritse B, Ghio S, St John Sutton M, Daubert JC. Effect of QRS duration and morphology on cardiac resynchronization therapy outcomes in mild heart failure: results from the Resynchronization Reverses Remodeling in Systolic Left Ventricular Dysfunction (REVERSE) study. Circulation. 2012; 126:822-829. [PubMed: 22781424]

16. Peichl P, Kautzner J, Cihak R, Bytesnik J. The spectrum of inter- and intraventricular conduction abnormalities in patients eligible for cardiac resynchronization therapy. Pacing Clin Eletrophysiol. 2004; 27:1105-1112.

17. McLeod CJ, Shen WK, Rea RF, Friedman PA, Hayes DL, Wokhlu A, Webster TL, Wiste HJ, Hodge DO, Bradley DJ, Hammill SC, Packer DL, Cha YM. Differential outcome of cardiac resynchronization therapy in ischemic cardiomyopathy and idiopathic dilated cardiomyopathy. Heart Rhythm. 2011; 8:377-382. [PubMed: 21070886]

18. Chen J, Garcia EV, Folks RD, Cooke CD, Faber TL, Tauxe EL, Iskandrian AE. Onset of left ventricular mechanical contraction as determined by phase analysis of ECG-gated myocardial perfusion SPECT imaging: Development of a diagnostic tool for assessment of cardiac mechanical dyssynchrony. J Nucl Cardiol. 2005; 12:687-695. [PubMed: 16344231]

19. Boogers MJ, Chen J, van Bommel RJ, Borleffs CJ, Dibbets-Schneider P, van der Heil B, AI Younis I, Schalij MJ, van der Wall EE, Garcia EV, Bax JJ. Optimal left ventricular lead position assessed with phase analysis on gated myocardial perfusion SPECT. Eur J Nucl Med Mol Imaging. 2011; 38:230-238. [PubMed: 20953608]

20. Van Train KF, Areeda J, Garcia EV, Cooke CD, Maddahi J, Kiat H, Germano G, Silagan G, Folks R, Berman DS. Quantitative same-day rest-stress technetium-99m-sestamibi SPECT: Definition and validation of stress normal limits and criteria for abnormality. J Nucl Med. 1993; 34:14941502. [PubMed: 8355069]

21. Chen J, Garcia EV, Bax JJ, Iskandrian AE, Borges-Neto S, Soman P. SPECT myocardial perfusion imaging for the assessment of left ventricular mechanical dyssynchrony. J Nucl Cardiol. 2011; 18:685-694. [PubMed: 21567281]

22. Galt JR, Garcia EV, Robbins WL. Effects of myocardial wall thickness on SPECT quantification. IEEE Trans Med Imag. 1990; 9:144-150.

23. Henneman MM, Chen J, Ypenburg C, Dibbets P, Stokkel M, van der Wall EE, Garcia EV, Bax JJ. Phase analysis of gated myocardial perfusion SPECT compared to tissue Doppler imaging for the assessment of left ventricular dyssynchrony. J Am Coll Cardiol. 2007; 49:1708-1714. [PubMed: 17448373]

24. Cerqueira MD, Weissman NJ, Dilsizian V, Jacobs AK, Kaul S, Laskey WK, Pennell DJ, Rumberger JA, Ryan T, Verani MS. Standardized myocardial segmentation and nomenclature for tomographic imaging of the heart. Circulation. 2002; 105:539-542. [PubMed: 11815441]

25. Samad Z, Atchley AE, Trimble MA, Sun JL, Shaw LK, Pagnanelli R, Chen J, Garcia EV, Iskandrian AE, Velazquez EJ, Borges-Neto S. Prevalence and predictors of mechanical dyssynchrony as defined by phase analysis in patients with left ventricular dysfunction undergoing 
gated SPECT myocardial perfusion imaging. J Nucl Cardiol. 2011; 18:24-30. [PubMed: 21082299]

26. Hawkins NM, Petrie MC, MacDonald MR, Hogg KJ, McMurray JJ. Selecting patients for cardiac resynchronization therapy: electrical or mechanical dyssynchrony? Eur Heart J. 2006; 27:12701281. [PubMed: 16527827]

27. Bax JJ, Bleeker GB, Marwick TH, Molhoek SG, Boersma E, Steendijk P, van der Wall EE, Schalij MJ. Left ventricular dyssynchrony predicts response and prognosis after cardiac resynchronization therapy. J Am Coll Cardiol. 2004; 44:1834-1840. [PubMed: 15519016]

28. Bleeker GB, Mollema SA, Holman ER, van de Veire N, Ypenburg C, Boersma E, van der Wall $\mathrm{EE}$, Schalij MJ, Bax JJ. Left ventricular resynchronization is mandatory for response to cardiac resynchronization therapy: analysis in patients with echocardiographic evidence of left ventricular dyssynchrony at baseline. Circulation. 2007; 116:1440-1448. [PubMed: 17785624]

29. Leyva F. Cardiac resynchronization therapy guided by cardiac magnetic resonance. J Cardiovasc Magn Reson. 2010; 12:64. [PubMed: 21062491]

30. Henneman MM, Chen J, Dibbets P, Stokkel M, Bleeker GB, Ypenburg C, van der Wall EE, Schalij MJ, Garcia EV, Bax JJ. Can LV dyssynchrony as assessed with phase analysis on gated myocardial perfusion SPECT predict response to CRT? J Nucl Med. 2007; 48:1104-1111. [PubMed: 17574987]

31. Toussaint JF, Lavergne T, Kerrou K, Froissart M, Ollitrault J, Darondel JM, Alonso C, Diebold B, Le Heuzey JY, Guize L, Paillard M. Basal asynchrony and resynchronization with biventricular pacing predict long-term improvement of LV function in heart failure patients. Pacing Clin Electrophysiol. 2003; 26:1815-1823. [PubMed: 12930495]

32. White JA, Yee R, Yuan X, Krahn A, Skanes A, Parker M, Klein G, Drangova M. Delayed enhancement magnetic resonance imaging predicts response to cardiac resynchronization therapy in patients with intraventricular dyssynchrony. J Am Coll Cardiol. 2006; 48:1953-1960. [PubMed: 17112984]

33. Adelstein EC, Saba S. Scar burden by myocardial perfusion imaging predicts echocardiographic response to cardiac resynchronization therapy in ischemic cardiomyopathy. Am Heart J. 2007; 153:105-112. [PubMed: 17174647]

34. Khan FZ, Virdee MS, Fynn SP, Dutka DP. Left ventricular lead placement in cardiac resynchronization therapy: where and how? Europace. 2009; 11:554-561. [PubMed: 19372115]

35. Ypenburg C, van Bommel RJ, Delgado V, Mollema SA, Bleeker GB, Boersma E, Schalij MJ, Bax JJ. Optimal left ventricular lead position predicts reverse remodeling and survival after cardiac resynchronization therapy. J Am Coll Cardiol. 2008; 52:1402-1409. [PubMed: 18940531]

36. Schwartzman D, Chang I, Michele JJ, Mirotznik MS, Foster KR. Electrical impedance properties of normal and chronically infarcted ventricular myocardium. J Interv Card Electrophysiol. 1999; 3:213-224. [PubMed: 10490477]

37. Reddy VY, Wrobleski D, Houghtaling C, Josephson ME, Ruskin JN. Combined Epicardial and Endocardial Electroanatomic Mapping in a Porcine Model of Healed Myocardial Infarction. Circulation. 2003; 107:3236-3242. [PubMed: 12796129]

38. Bleeker GB, Kaandorp TA, Lamb HJ, Boersma E, Steendijk P, de Roos A, van der Wall EE, Schalij MJ, Bax JJ. Effect of postero-lateral scar tissue on clinical and echocardiographic improvement after cardiac resynchronization therapy. Circulation. 2006; 113:969-976. [PubMed: 16476852]

39. Friehling M, Chen J, Saba S, Bazaz R, Schwartzman D, Adelstein EC, Garcia EV, Follansbee WP, Soman P. The relationship between acute change in LV mechanical synchrony after cardiac resynchronization therapy and patient outcome: Prospective evaluation by a novel, singleinjection, gated-SPECT protocol. Circ Cardiovasc Imaging. 2011; 4:532-539. [PubMed: 21772007] 


\section{Gated SPECT MPI \\ First-Harmonic} Perfusion Polar Map

8

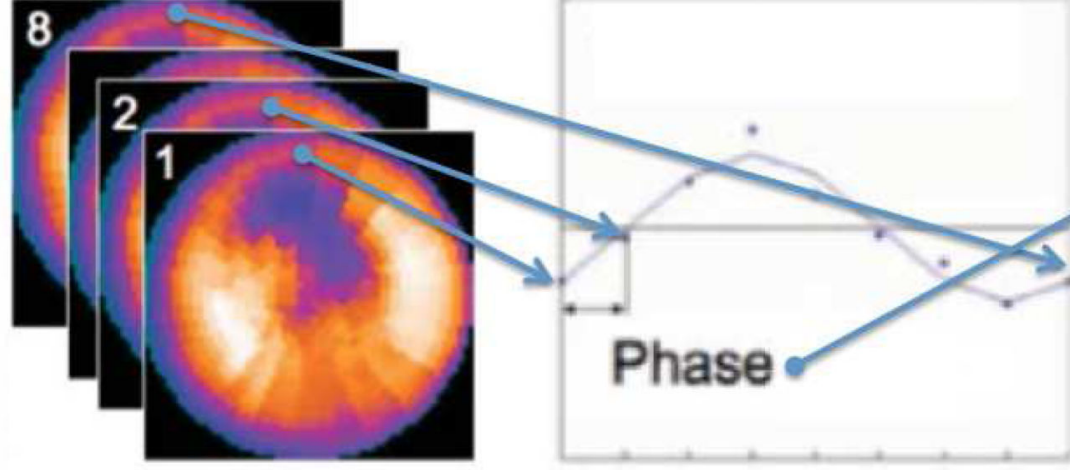

2

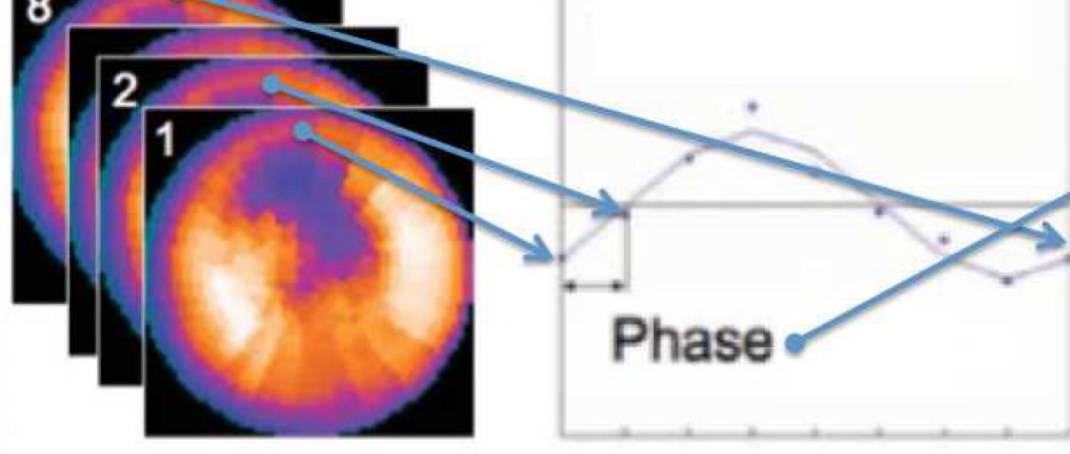

Approximation

A. The first-harmonic phase analysis

B. The phase polar map

Figure 1.

Demonstration of the phase analysis technique to measure the regional onset of mechanical contraction over the left ventricle. 


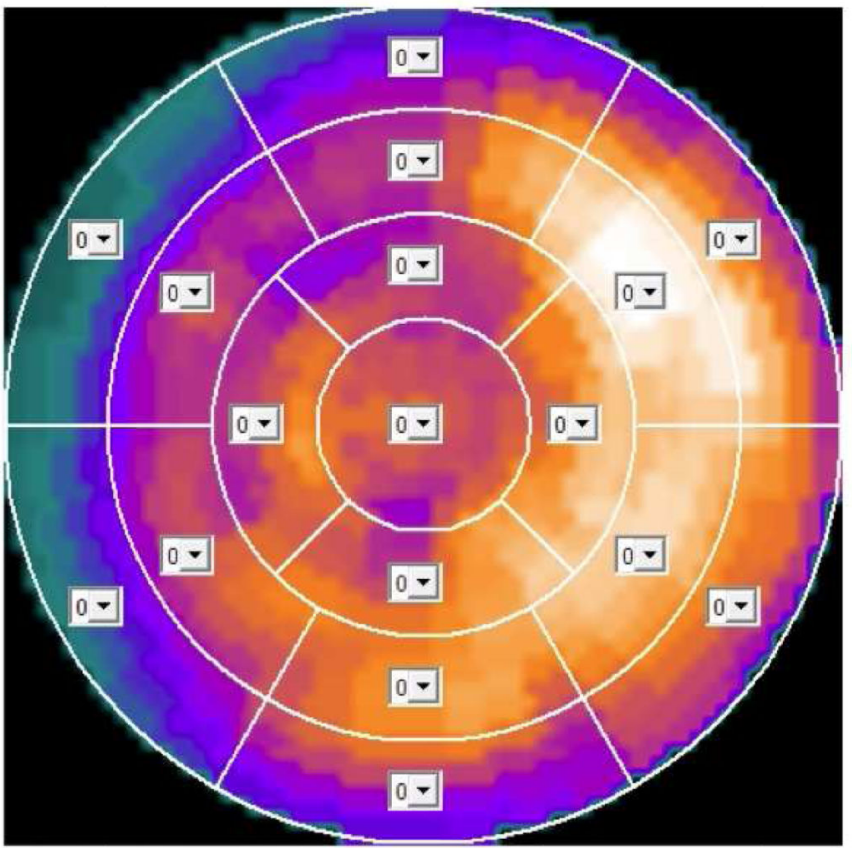

A. Perfusion polar map in the 17-segment model

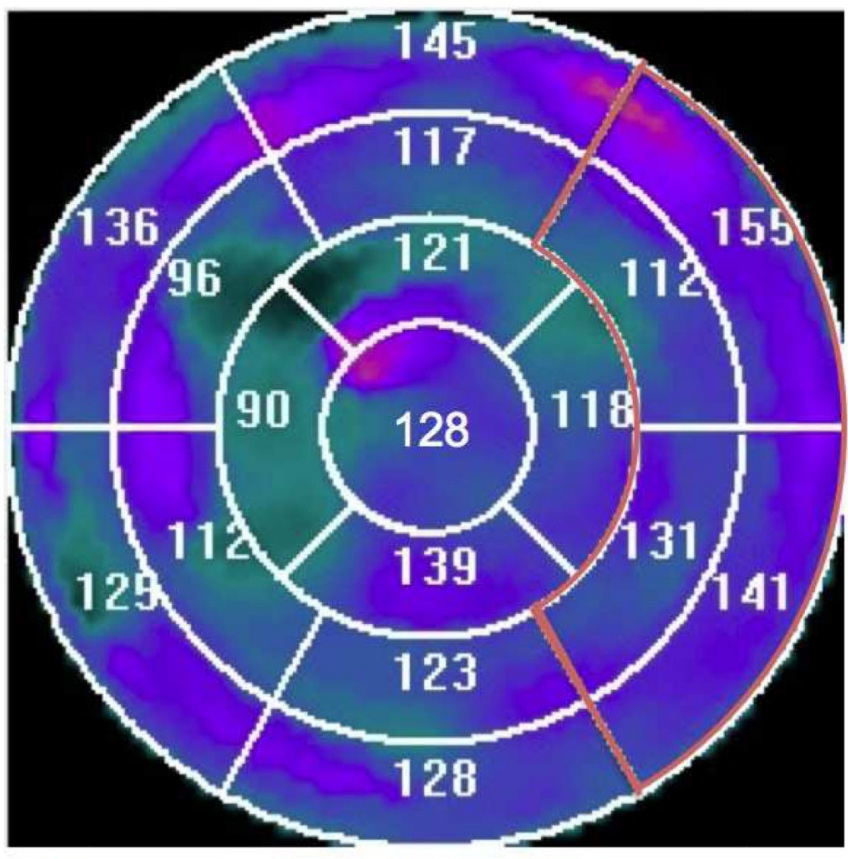

B. Phase polar map in the 17-segment model

Figure 2.

An example patient with LBBB, wide QRSd (170 ms), and dilated cardiomyopathy. The perfusion polar map in the 17-segment model shows the perfusion score of each segment (0 $=$ normal, $1=$ equivocal, $2=$ moderately reduced, $3=$ severely reduced, $4=$ absent). The phase polar map in the 17-segment model shows the mean phase of each segment, representing the timing of the segmental mechanical activation. This patient had a normal myocardial perfusion (score $=0$ for all segments), and the site latest mechanical activation (mean phase $=155^{\circ}$, the largest mean phase among the 17 segments) was one of the highlighted lateral segments. 


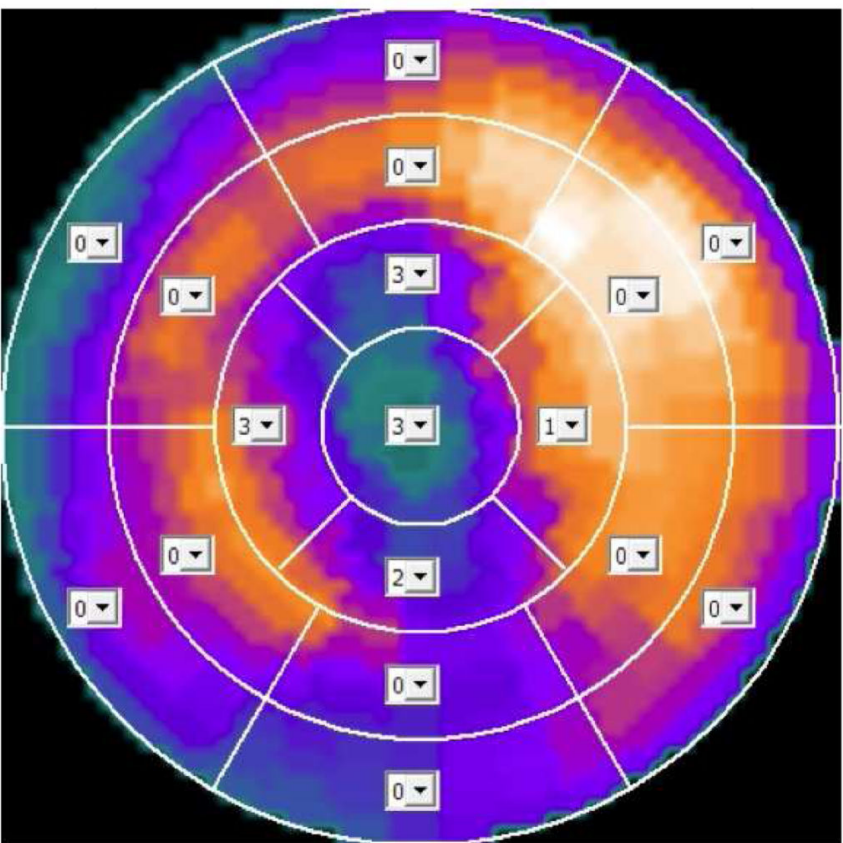

A. Perfusion polar map in the 17-segment model

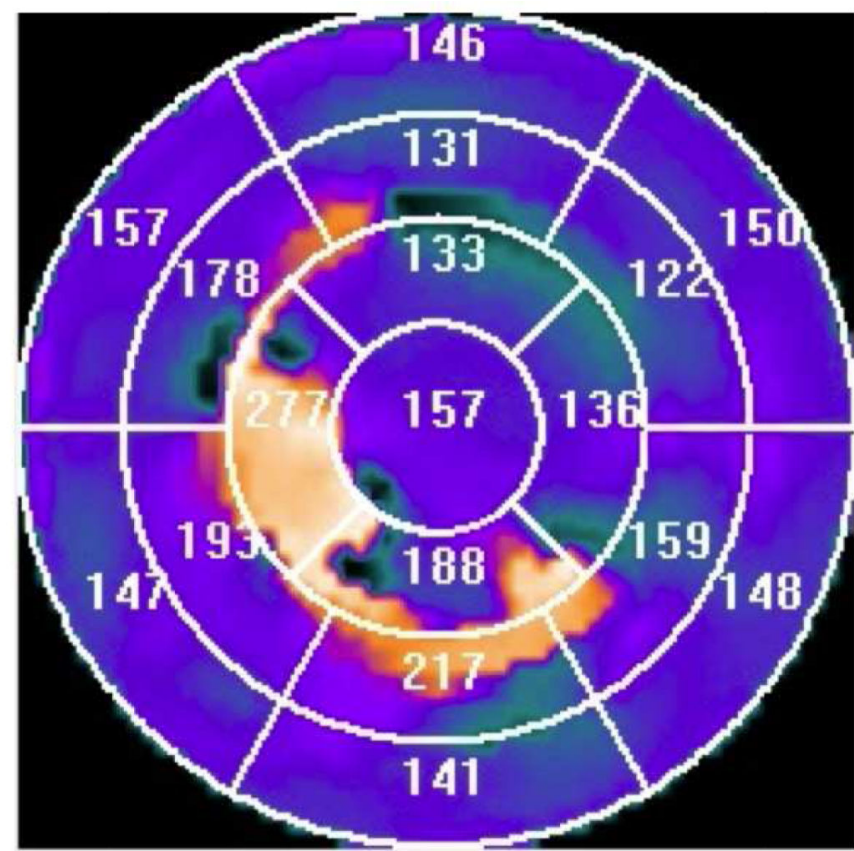

B. Phase polar map in the 17-segment model

Figure 3.

An example patient with LBBB, wide QRSd (160 ms), and ischemic cardiomyopathy. The perfusion polar map in the 17-segment model shows the perfusion score of each segment (0 $=$ normal, $1=$ equivocal, $2=$ moderately reduced, $3=$ severely reduced, $4=$ absent). The phase polar map in the 17-segment model shows the mean phase of each segment, representing the timing of the segmental mechanical activation. The site of latest mechanical activation (mean phase $=277^{\circ}$, the largest mean phase among the 17 segments) was in the myocardial scar, which spreads over the apical segments (score $=3$ ). The scar also caused late mechanical activation in the segments adjacent to the site of latest mechanical activation, which had relatively larger mean phases than other segments. 
Pre-CRT dyssynchrony ( $\mathrm{PSD}=37^{\circ}, \mathrm{PHB}=95^{\circ}$ ) and functional parameters

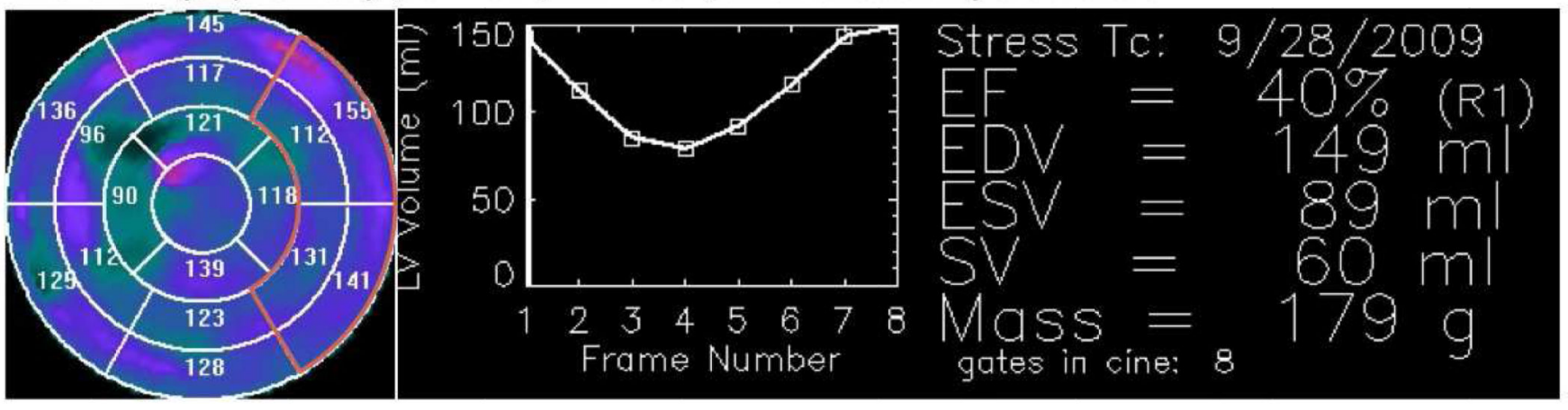

\section{Post-CRT dyssynchrony (PSD $\left.=26^{\circ}, \mathrm{PHB}=68^{\circ}\right)$ and functional parameters}
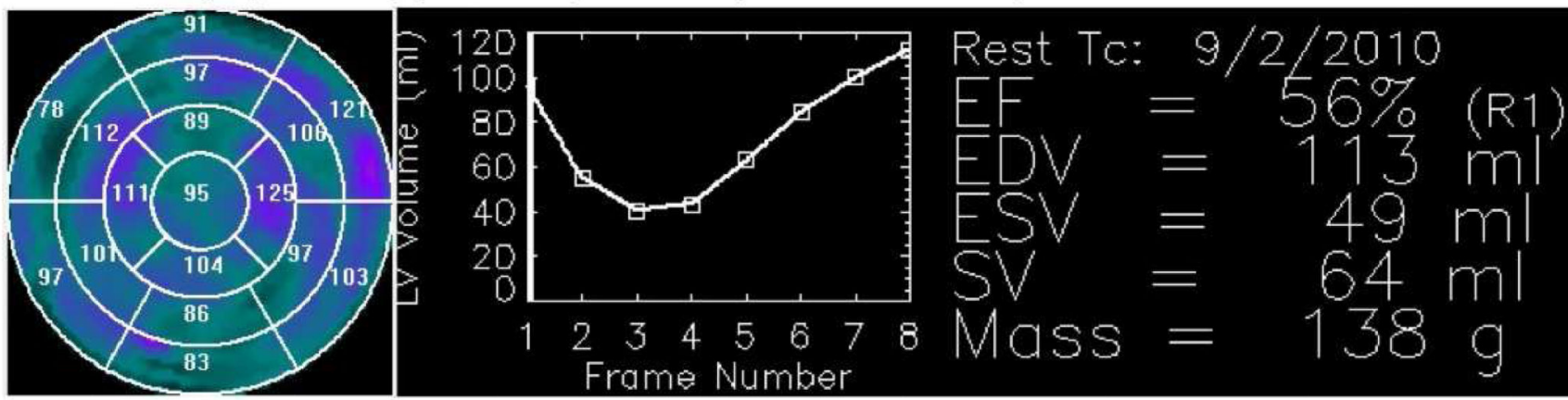

Figure 4.

The pre-CRT and post-CRT dyssynchrony and functional parameters of the example patient in Figure 2. This patient had a standard CRT implantation within one month after the first SPECT scan, and the second SPECT scan was acquired about eleven months post CRT. This patient had DCM, LBBB and wide QRSd (170 ms), and LV dyssynchrony. Her lateral wall was viable and had the latest mechanical activation. After the standard CRT therapy this patient showed remarkable improvement in LV synchrony and LVEF, and reduction in LV end-diastolic and end-systolic volumes, representing a positive CRT response and LV reserve remodeling. 
Table 1

\section{Patient Characteristics}

\begin{tabular}{|l|l|l|}
\hline & $\begin{array}{l}\text { Ischemic Cardiomyopathy } \\
(\mathbf{N = 1 7})\end{array}$ & $\begin{array}{l}\text { Dilated Cardiomyopathy } \\
(\mathbf{N = 4 7})\end{array}$ \\
\hline Age (year) & $63.8 \pm 14.6$ & $64.1 \pm 11.8$ \\
\hline Gender (M/F) & $9 / 8(53 \%)$ & $27 / 20(57 \%)$ \\
\hline NYHA class & $3.2 \pm 0.4$ & $3.1 \pm 0.7$ \\
\hline QRS duration (ms) & $144 \pm 23$ & $153 \pm 16$ \\
\hline Summed rest score & $23.8 \pm 10.0 *$ & $3.7 \pm 3.6^{*}$ \\
\hline LVEF $(\%)$ & $26.6 \pm 7.9$ & $26.8 \pm 8.9$ \\
\hline LV end-systolic volume $(\mathrm{mL})$ & $110.6 \pm 46.8^{*}$ & $160.8 \pm 70.3^{*}$ \\
\hline LV end-diastolic volume $(\mathrm{mL})$ & $145.9 \pm 62.6^{*}$ & $212.7 \pm 86.5^{*}$ \\
\hline
\end{tabular}

* Statistical significance $(\mathrm{p}<0.05)$ by the unpaired $\mathrm{t}$ test with unequal variance 


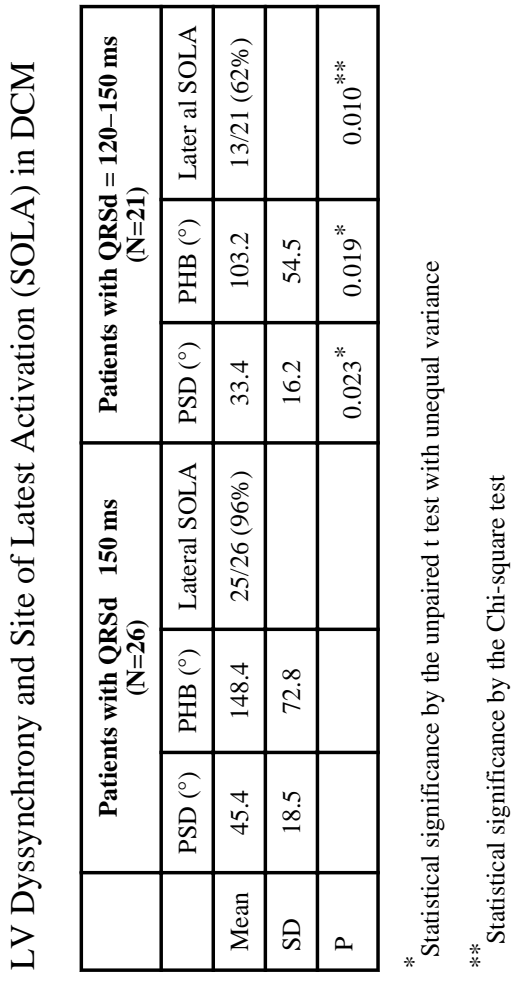


Table 3

LV Dyssynchrony and QRSd in ICM vs. DCM

\begin{tabular}{|l|l|l|l|l|}
\hline \multirow{2}{*}{$\begin{array}{l}\text { Patients with ICM } \\
(\mathbf{N = 1 7 )}\end{array}$} & \multicolumn{3}{|c|}{ Patients with DCM } \\
\cline { 3 - 5 } & & $\begin{array}{l}\text { Entire Group } \\
(\mathbf{N = 4 7})\end{array}$ & $\begin{array}{l}\text { QRSd } \mathbf{1 5 0} \text { ms } \\
(\mathbf{N = 2 6})\end{array}$ & $\begin{array}{l}\text { QRSd <150 ms } \\
(\mathbf{N = 2 1})\end{array}$ \\
\hline PSD $\left.^{(}{ }^{\circ}\right)$ & $50.6 \pm 20.6$ & $40.0 \pm 18.3^{*}$ & $45.4 \pm 18.5$ & $33.4 \pm 16.2^{*}$ \\
\hline PHB $\left(^{\circ}\right)$ & $171.9 \pm 83.8$ & $128.2 \pm 68.5^{*}$ & $148.4 \pm 72.8$ & $103.2 \pm 54.5^{*}$ \\
\hline QRSd (ms) & $144 \pm 23$ & $151 \pm 16$ & $163 \pm 11^{*}$ & $138 \pm 7$ \\
\hline
\end{tabular}

Unpaired t test was used compare the ICM patients to the DCM patients as an entire group and as in two sub-groups with wide and moderate QRS durations, respectively.

Statistical significance by the unpaired $\mathrm{t}$ test with unequal variance $(\mathrm{p}<0.05)$ 